\title{
The Superconducting Magnet System of the Stellarator Wendelstein 7-X
}

\author{
Thomas Rummel, Konrad Riße, Gunnar Ehrke, Kerstin Rummel, Andre John, Thomas Mönnich, Klaus-Peter Buscher \\ Max-Planck-Institut für Plasmaphysik, Euratom Association \\ Greifswald, Germany \\ Thomas.Rummel@ipp.mpg.de \\ Walter H. Fietz, Reinhard Heller \\ Karlsruhe Institute of Technology \\ Karlsruhe, Germany \\ Olaf Neubauer, Anatoly Panin \\ Forschungszentrum Jülich \\ Jülich, Germany
}

\begin{abstract}
The stellarator fusion experimental device Wendelstein 7-X (W7-X) is presently under assembly at the Greifswald branch of the Max-Planck-Institut für Plasmaphysik (IPP), Germany. The superconducting magnet system consists of 50 non planar coils, 20 planar coils, a superconducting bus system and 14 current leads. It is organized in seven electrical circuits with ten coils, the bus system for the interconnection and two current leads each. The magnet system is cooled by supercritical helium. It is enclosed in a cryostat with an outer diameter of $\mathbf{1 6}$ meters formed by the plasma vessel and the outer vessel. There are five different types of non planar coils having dimensions of $3.5 \times 2.5 \times 1.5$ meters in maximum and a weight of about 5.5 tons. The two different types of the planar coils are nearly circular coils with a diameter of up to 4.5 meters and a weight of about 3 tons. The superconducting bus bar system connects the coils to each other and provides the connection to the current leads inside the cryostat. All types of coils and the bus system use the W7$X$ superconductor, a forced flow cable-in-conduit superconductor with 243 copper stabilized NbTi strands with an outer aluminumalloy jacket. The current leads provide the transfer of the electrical current from the room temperature bus bar system outside the cryostat to the superconducting parts inside the cryostat. Their special feature is the upside down orientation with the cold end at the top.
\end{abstract}

Keywords- Wendelstein 7-X; superconducting magnet system, coils, bus bars, current leads

\section{INTRODUCTION}

This stellarator fusion experimental device Wendelstein 7-X (W7-X) is presently under assembly at the Greifswald branch of the Max-Planck-Institut für Plasmaphysik (IPP), Germany. One of its most important aims is to demonstrate the ability of steady state operations and the reactor relevance of stellarators for a nuclear fusion power plant. Advantages of a stellarator for a fusion power plant are the inherent capability of steady-state operation and the absence of fast plasma disruptions. To allow the steadystate operation, W7-X has a superconducting magnet system. It consists of 50 non planar coils, 20 planar coils, a superconducting bus system and 14 current leads. The coils are individually fixed on a central support ring and supported against each other. They are arranged toroidally in five equal modules. Each of the modules consists of two mirror symmetric half modules. The coil system of one half module consists of five different non planar coils and two different planar coils (Fig. 1). 


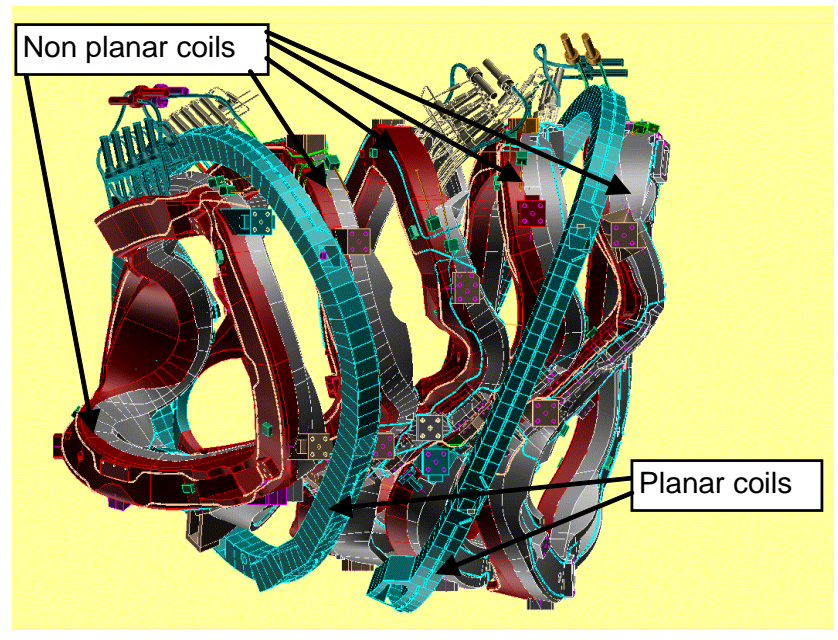

Figure 1. One half module of the W7-X magnet system.

The magnet system is cooled by supercritical helium. It is enclosed in a cryostat with an outer diameter of 16 meters formed by the plasma vessel and the outer vessel.

In the following sections the main parts of the superconducting magnet system will be described.

\section{SUPERCONDUCTOR}

Three of the four main superconducting components are using the same type of superconductor. It is a forced flow cable-inconduit conductor using $\mathrm{NbTi}$ [1]. It consists of a cable with 243 strands enclosed in an aluminum-alloy jacket with a void fraction of $37 \%$. The outer dimensions of the jacket are $16 \mathrm{~mm}$ x $16 \mathrm{~mm}$. The inner side is nearly circular with a diameter of $11.7 \mathrm{~mm}$ (Fig. 2).

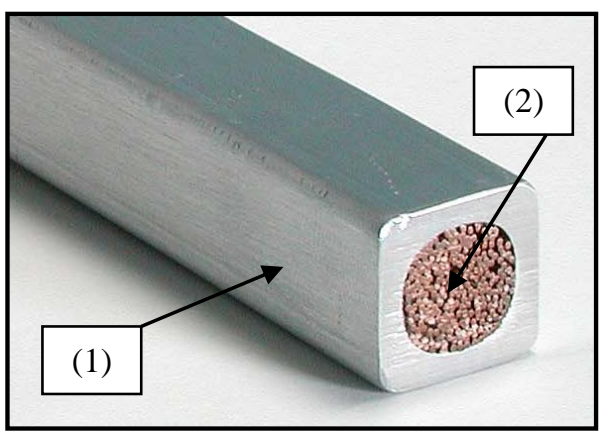

Figure 2. W7-X supercoductor, mainly consistin of the aluminium-alloy jacket (1) and the cable (2), made of 243 strands.

The design of three dimensional coils led to the requirements of a bending with a minimum bending radius of $120 \mathrm{~mm}$. The conductor jacket has to be soft enough to allow the bending work during the coil production and on the other hand it has to be stable enough to carry the loads during operation. Therefore an aluminum alloy (AlMgSi0.5) was chosen as jacket material. The yield strength (Rp02) is smaller than $150 \mathrm{MPa}$ in soft condition at room temperature and greater than $280 \mathrm{MPa}$ in hardened condition at 7 Kelvin.

Each strand has a diameter of $0.57 \mathrm{~mm}$ and is made of $144 \mathrm{NbTi}$ filaments stabilized by copper with a copper to non-copper ratio of 2.6. The specified critical current of the superconductor is $35 \mathrm{kA}$ at $4 \mathrm{~K}$ and 6 Tesla background field. This gives a temperature margin of about 1 Kelvin for the coils during operation. 
The production of the superconductor was performed by a consortium consisting of the former Vacuumschmelze (VAC, today Bruker EAS), Hanau, Germany and Europa Metalli (EM, today Outokumpu), Fornaci di Barga, Italy. The share of the work was organized in the following way: The production of the strands was shared equally between VAC and EM. The cabling was done at EM for all the cables, the co-extrusion process, where the aluminum was formed around the conductor, was organized by VAC and performed by ALU Menziken, Switzerland. The testing of the fabricated conductors ran completely at EM in Italy. This share of work was the real organizational challenge, as the responsibility changes several times and also crossing several borders turned out to be an underestimated time driver.

The technical challenge was the step from the prototype to the series production. Two main issues, the cabling and the coextrusion, were identified as the most critical steps. The cabling turned out to be more difficult than expected, because the strands of the two manufacturers were slightly different in terms of surface roughness and mechanical properties. Also the cabling law of $3 \times 3 \times 3 \times 3 \times 3$ leads to a relative non uniform cable with the associated problems during the cabling process [1]. The co-extrusion process was performed on a machine which was occupied $90 \%$ of the time by the production of components for large airplanes, so the co-extrusion of the W7-X superconductor ran in the shadow of the other job. From the technical point of view the most challenging task was the proper selection of the tooling, depending on the quality of the rope and to maintain the required helium flow rate and void fraction for all the produced conductor lengths. The helium flow rate was an important issue for the coil production, because all the conductors in the non planar coils and in the planar coils, respectively, are hydraulically connected in parallel without any cold valve for adjustment.

In total 390 so-called double layer lengths were produced with lengths between 120 and 130 meters for the planar coils and from 150 to 170 meters for the non planar coils. The total amount of superconductor was about $60 \mathrm{~km}$, made of about $15000 \mathrm{~km}$ of strands.

Twelve lengths, sufficient for two non planar coils or four planar coils or one non planar coil and two planar coils, have been ordered by IPP as spares.

\section{NON PLANAR COILS}

\section{A. Overview}

The main magnetic field of W7-X will be achieved by the non planar coils [3]. They combine the functions of the helical coils and of the toroidal field coils from a classical stellarator. The combination leads to three dimensional coils (Fig. 1). Fifty non planar coils are necessary in W7-X. Due to the five fold symmetry of the stellarator and the flip symmetric installations of two identical half modules five differently shaped coils are necessary. They differ in the shape of the winding pack and in addition also in the shape of the coil casing due to necessary stiffening measures. They are identical regarding their winding principles. All non planar coils consist of 108 turns, divided into six double pancakes, which are wound from one continuous length each. Electrically the six double pancakes are connected in series by so-called interlayer joints with a resistance of maximum 1 nano Ohm. An interlayer joint consists of an aluminium housing and an internal copper block. The jackets of the conductors of two adjacent layers are welded to the housing. The cables are fed into the housing and soldered into two holes in the block (Fig. 3).

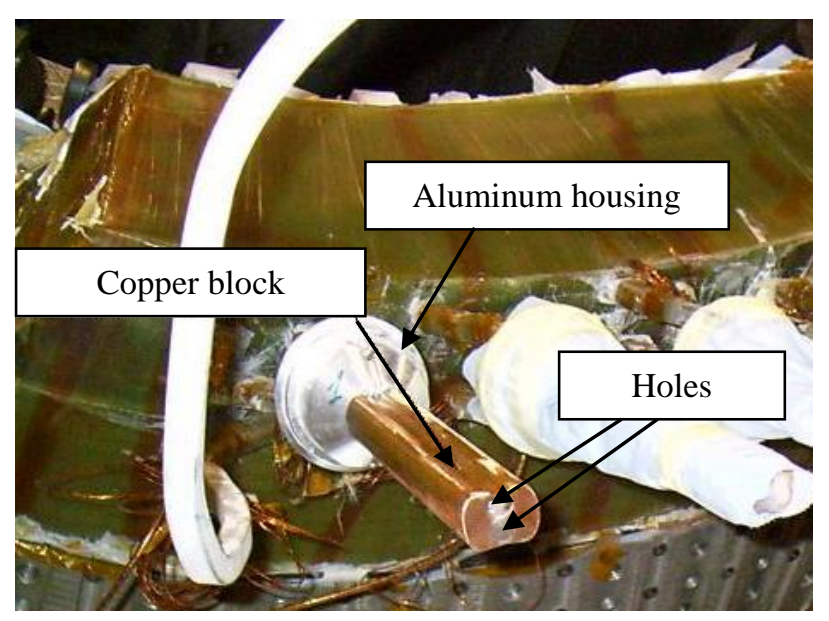

Figure 3. Interlayer joint during the production. 
Hydraulically the double pancakes are connected in parallel. The hydraulic connection scheme secures that the innermost layer (high field layer) always gets the fresh helium from the inlet. All the non planar coils are designed for a nominal current of $17.6 \mathrm{kA}$, with dimensions of about $3.5 \times 2.5 \times 1.5$ meters in maximum and a weight of approximately 5.5 tons each. The coil insulation system is designed for a nominal voltage to ground of $6 \mathrm{kV} \mathrm{d}$. c. and a related test voltage of $13 \mathrm{kV} \mathrm{d}$. c. during the acceptance test at room temperature.

\section{B. Winding pack production}

The production of the non planar coils was the responsibility of a consortium formed by Babcock Noell Nuclear (BNN, today BNG), Germany and Ansaldo Superconduttori (ASG), Italy, with the following share of the winding work. Ansaldo has produced 30 winding packs and BNN subcontracted the other 20 winding packs to ABB in Augsburg, Germany. The work comprised also the application of the insulation to ground which consists of glass fiber tapes with hot curing epoxy resin with a final thickness of $5 \mathrm{~mm}$. Both companies have used their own technology of the vacuum pressure impregnation. One company used a very rigid impregnation mould, the other used the winding form as basis for the impregnation and applied stiffening and tightening plastic plates to form the smooth impregnation mould. Also the orientation of the winding pack differs during impregnation (horizontal vs. vertical orientation). It can be concluded that the rigid impregnation mould gave the more stable process and that the vertical orientation is necessary to avoid air inclusions in three dimensional winding packs.

The final dimensional measurement of the winding packs after impregnation was done with a Laser measurement device. Dimensional checks have shown that the contour is reproducible with statistical deviations within $1.5 \mathrm{~mm}$ band only. The data from the survey of each single winding pack are transferred to eight measurement marks on the surface, these measurement marks are accessible during the production process and are used for adjustments of the coils during the assembly into the W7-X, too [2].

Fig. 4 shows a winding pack after impregnation and already equipped with conductive paint.

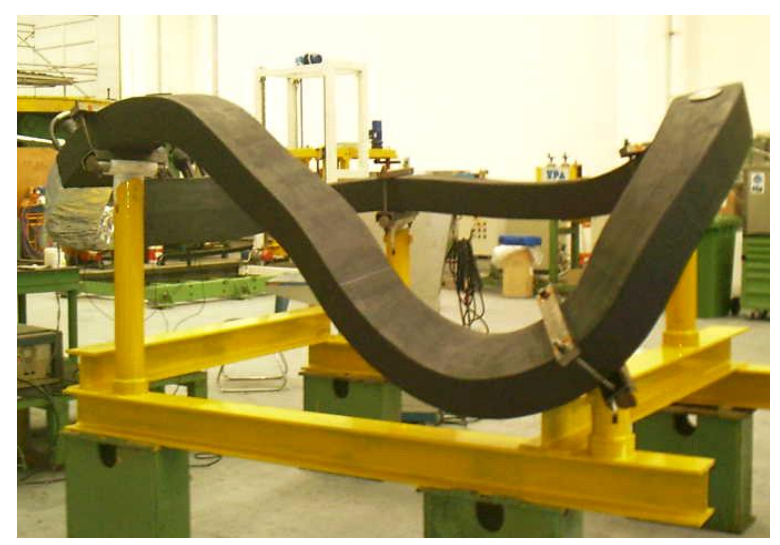

Figure 4. Winding pack of a non planar coil.

\section{Coil casing production}

Each winding pack is stiffened by a massive stainless steel case to withstand the electromagnetic forces. The case is divided into two halves to allow the insertion of the winding pack. The half cases were manufactured by casting. The integrity of the half shells was verified by $\mathrm{x}$-ray and dye penetrant tests. Several casting defects like pores and inclusions were found, a special working group had to be settled to evaluate the importance of the defects case by case and to define the necessary repair actions.

\section{Coil assembly}

The coil assembly took place at Babcock Noell Magnettechnik GmbH in Zeitz, Germany. The winding pack was inserted into one of the two half case sub-assemblies and the other half is brought into place, and both half cases are welded together by using TIG welding for the root, followed by the dye penetrant test, and MAG welding for the filler layers. The gap between winding pack and case was filled with quartz sand and impregnated with cold cure resin.

A number of interfaces on the coils as well as some surfaces require a final machining. In general, the surface of the coil is machined to maintain the specified tolerance of $5 \mathrm{~mm}$, except on the plasma side, where the tolerance is $3 \mathrm{~mm}$. A higher accuracy is required for areas where the coil comes in defined contact with other coils or where they are fixed to the support structure of W7-X. Because they define the position of the coil in the machine and consequently the quality of the magnetic field in W7-X all these surfaces as well as the threaded holes are required to be machined with an accuracy between 0.1 and $0.3 \mathrm{~mm}$. Most of these 
interfaces were subjected to a serious rework, caused by a heavy design change. Also already completed coils had to be reworked again to fit to the new design.

The final fabrication step was the application of the active cooling shield. Roughly 1100 copper stripes are welded around the case and soldered to four cooling pipes (see items (2) and (3) in Fig. 5).

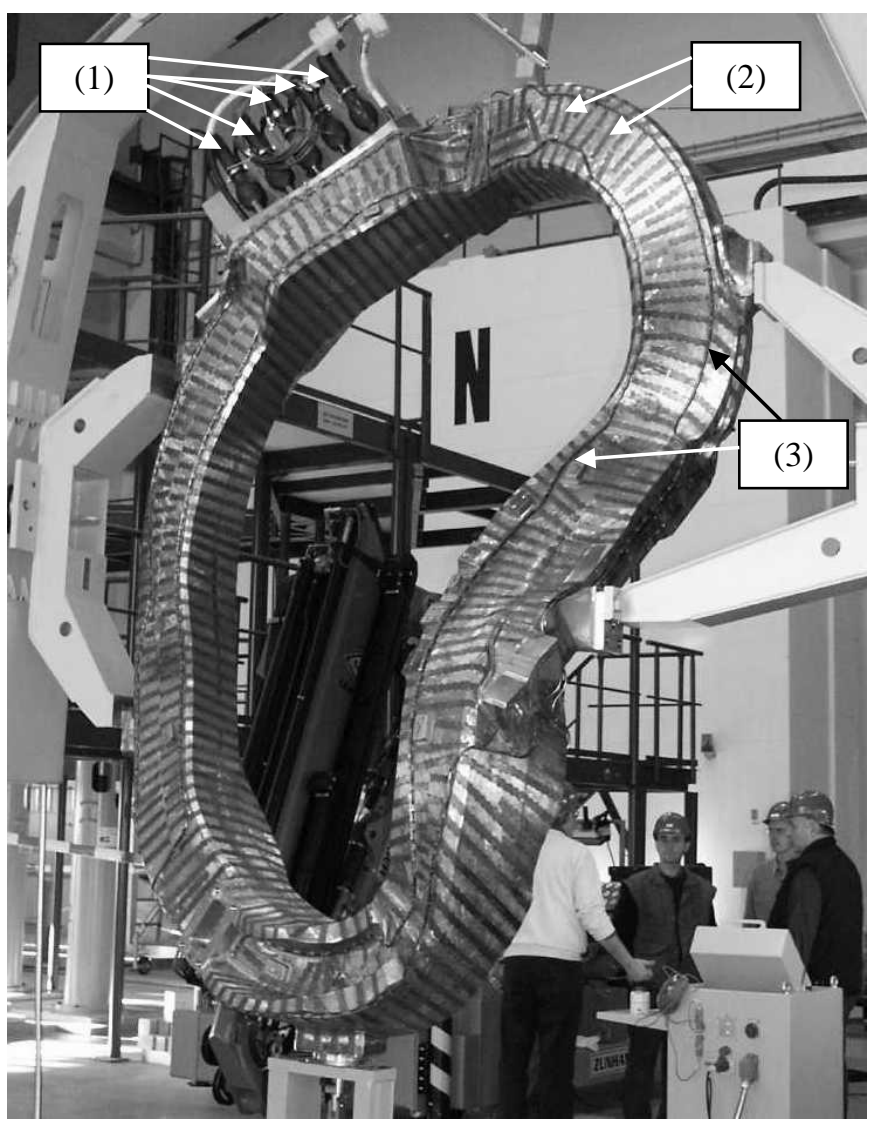

Figure 5. Non planar coil type 1, showing interlayer joints (1), copper strips (2) and cooling channels (3) of the cooling shield.

\section{E. Summary}

The contract was placed in 1998, the production started in 2001, delayed by the conductor production, and was interrupted in 2002 due to the insolvency of the consortiums-leader. The first coil was produced in 2003. In the following years the production rate of one to two magnets per months was established, but was affected regularly by repair actions on the Quench detection cables (QD cables), on the interlayer insulation as well as on the joint- and connection area. Other repairs had to be performed on the coil casings (casting defects). Also design changes at the mechanical interfaces and the casing cooling tubes routing had to be done [4]. In total 1500 non conformity reports were handled. The last coil was produced in 2008, 3.5 years later than originally fixed in the contract.

The main message is that three dimensional coils can be produced in a reproducible quality. Manufacturing problems were mainly subjected to standard fabrication processes like welding and insulation work, which are independently from the shape of the coils. 


\section{PlanAR COILS}

\section{A. Overview}

The planar coils in W7-X are used to change the magnetic configuration e.g. in terms of shear, jota and mirror. They also allow a shift of the plasma more in- or outwards. The planar coils are assembled over the non planar coils at an angle of around 20 degrees with respect to the main vertical axis.

The 20 planar coils are divided into two different types, type A and type B coils, with ten coils of each type. Each coil has a typical weight of around 3 tons and an outer diameter of approximately 4 meters. The coils are wound from the standard W7-X conductor. The nominal current is $16 \mathrm{kA}$. The coil insulation system is designed for a nominal voltage to ground of $4 \mathrm{kV} \mathrm{d}$. c. and a related test voltage of $9 \mathrm{kV} \mathrm{d}$. c. during the acceptance test at room temperature. The main components of the planar coils are (see Fig. 6): the winding pack, the steel case, the case cooling system and the lead and instrumentation area.

\section{B. Winding pack production}

The winding pack is made from three double pancakes with twelve turns each, connected electrically in series by two interlayer joints with a resistance of less than 1 nano Ohm. Hydraulically the double pancakes are connected in parallel with a similar schema than the non planar coils. The electrical insulation process (vacuum pressure impregnation) is similar to that of the non planar coils with the exception of using a primer before the application of the glass tape. The lead area is insulated manually using cold cure resin and glass tapes.

The achieved accuracy was quite good, the accuracy with respect to the CAD model was close to the limit of $5 \mathrm{~mm}$, but the deviation between the winding packs of the same type are very small, and are in the range of one millimeter.

\section{Coil casing production}

The case production is completely different from that of the non planar coils. Instead of casting of half rings, the casings of the planar coils were made from stainless steel plates. Plasma cut segments were welded to an outer ring, an inner ring, a base plate and a lid. The connection between base plate as well as the lid (after inserting of the winding pack) and the rings was made by nearly 400 screws. In mechanically highly loaded areas shear pins support the screws.

\section{Coil assembly}

The coil assembly comprises mainly the integration of the winding pack into the steel case. To achieve a pre-compression of the winding pack, the case was heated up to 150 degrees Celsius, then the winding pack was inserted and the gap was blocked with G11 filler pieces. After that the voids in coil case were filled up with glass balls and a warm cured resin in an autoclave. In a next step the forged blocks are welded to the case in order to fix the coil to the support structure and to the non planar coils. The final machining of the interface blocks with tolerances of some tenths of a millimeter turned out to be more difficult than expected, because of the large diameter of the coil and effects of dead weight and long measurement distances.

To minimize the heat load from the outer vessel shell all coils are equipped with a radiation shield made of copper plates which are tack welded to the coil case and soldered to a cooling tube. Ninety six segments of $100 \mathrm{~mm}$ width and $1 \mathrm{~mm}$ thickness were placed, the gap in between the segments shall reduce the heat generation by eddy current in case of a rapid change of the field. 


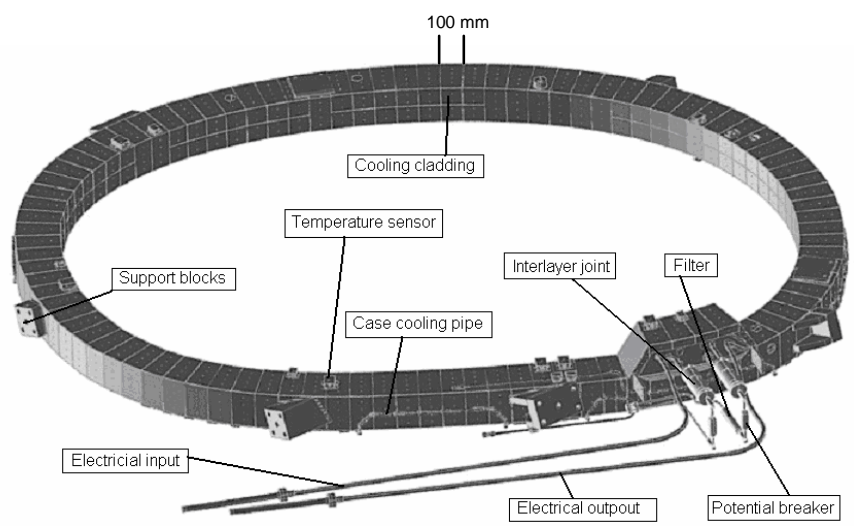

Figure 6. Planar coil type B.

\section{E. Summary}

The company Tesla Engineering Ltd. was contracted for the manufacture of the planar coils. The contract was placed in 1999, the production started in 2001, after the delay caused by the lack of the conductor, and led to the production of the first coil in 2003. In the following years a stable production was established, but was affected by the qualification of a new QD cable and the replacement of the old ones, repairs on the insulation in the joint and connection area, and design changes at the coil casing, the mechanical interfaces, the qualification of a proper soldering process, which avoids the danger of pit corrosion [5]. The last coil was produced in 2007 , five years later than originally fixed in the contract.

\section{COIL TESTS Under CRYOGENIC CONDITIONS}

There were several tests during the production and after the completion of the coils at room temperature. The final acceptance test was performed at all coils at cryogenic temperature. The main objective was to demonstrate the capability of the coil to work properly under cryogenic conditions, therefore the superconducting behavior had to be checked. The test facility at CEA Saclay, France, was equipped with two cryostats, each can be loaded with two coils and the cool-down of one cryostat with two coils took about ten days. The test procedure comprises the following tests at liquid He temperature: operation of the coil at nominal current in self field, quench and safety margin test, flow test, leak test, high voltage (HV) test, measurement of the residual resistance ratio (RRR) and interlayer joint resistance, stress and deformation measurements. HV test, leak test, flow test and check of coil instrumentation were performed before the cryogenic tests as part of the incoming inspection and after the cryogenic tests as outgoing checks.

Fig. 7 shows a typical test run under cryogenic conditions. The coils have been energized in several steps until its nominal current. The temperatures of the case also increase after a certain delay which depends on the position of the sensor. Then a quench was initiated by increasing the inlet temperatures (not shown in Fig. 7) in steps of 0.1 Kelvin. After recovering the coil was energized again to check and to compare the behavior. The second run has been done always at lower temperature levels. Therefore the overall helium temperature was reduced by 0.3 Kelvin at the inlet. The outlet temperature and the case temperatures are also about $0.3 \mathrm{~K}$ lower (after a certain transition time). This shows the stable operation of the coil at different temperature levels.

Also a partly ramp up and down was performed to check if the coil casing deformation is still elastically and not plastically (Fig. 7 , second run). No sign for plastic deformations were found. This was measured by using strain gauges, which are placed at two different locations at each coil. 


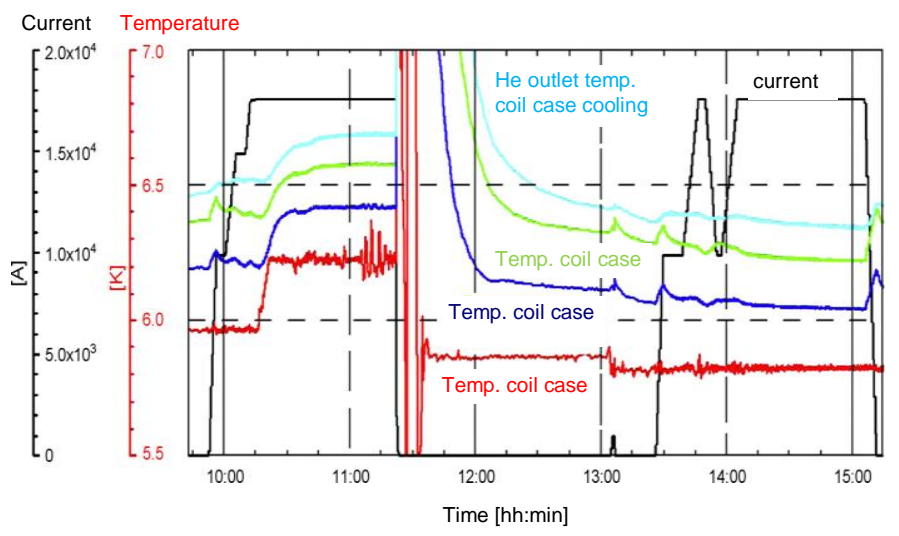

Figure 7. Typical test run during the cold test of a coil.

In total 98 cold tests were performed at the 70 coils between 2003 and 2008, several coils were tested twice and three coils were tested three times.

It can be concluded that all coils passed finally the test. No coil had to be rejected due to abnormal superconducting behavior. The safety margin tests confirmed for all coils a stable operation with a safety temperature margin of more than 1 Kelvin. Two coils of each type were subjected to a quench test. The measured quench temperatures are in all cases $0.15 \mathrm{~K}$ or even more better than predicted. On the other hand several cold leaks were found, mainly at aluminum welds. Other detected failures were malfunction of strain gauges and detached strain gauges, respectively [6].

The comparison between non planar and planar coils shows that three dimensional bending does not have negative influences to the superconductor's performance.

\section{BUS BAR SYSTEM}

The superconducting bus bar system connects the coils to each other and provides the connection to the current leads inside the cryostat. Fig. 8 shows a schematic view of the bus bar system of one magnet module of W7-X.

The electrical insulation system consists of Kapton foils, embedded in glass fiber tapes with epoxy resin. In total 121 bus bar sections with lengths between 4.5 and 16 meters were manufactured. The connection of the bus bars and the coils will be done by 184 joints with a maximum allowable resistance of 5 nano $\mathrm{Ohm}$ each. The design of the bus bar joints is different from the design of the interlayer joints of the coils, because the bus bar joints have to be de-mountable. This simpler design leads to the higher resistance compared with the interlayer joints of the coils.

The bus bar system [7] is designed for operating currents of up to $18.2 \mathrm{kA}$, high mechanical load (up to $11 \mathrm{kN} / \mathrm{m}$ ), differential thermal expansion, displacement of coils under load, pressure and leak tightness (17 MPa in case of a quench), high voltage capability (13 kV d.c.), low magnetic stray field generation (bifilar routing wherever possible). The joints had to be designed for low resistance (less than $5 \mathrm{nOhms}$ ) and for possible repair and replacement after assembly [8], [9]. Numerous interfaces and geometric boundary conditions defined the available space for the bus bars and their support elements and the joints. The design of the coils and the central support ring of the magnet system define the routing and available reference surfaces for supports. The restrictions due to the assembly requirements increase the complexity of design. Finally as-build geometry deviations of reference surfaces had to be considered. This condition requests for adjustment capabilities, especially of the supports.

The bus bar insulation has to withstand the electrical field corresponding to a test voltage of $13 \mathrm{kV}$ even after multiple mechanical as well as thermal load cycles. In order to guarantee the high-voltage withstand capability, even after a failure of an insulation layer, the insulation concept involves two layers of Kapton foil being $50 \%$ overlapped each, embedded in epoxy resin impregnated glass fiber layers.

Also the bus bars use the W7-X superconductor, but with slightly changed outer dimension to allow better bending of the three dimensional routing. The square shaped cross section was machined to an almost round one (17 mm diameter). Since manual bending of the bus bars (up to 25 steps each) and verification of the geometry would be too time-consuming a computer controlled bending machine was chosen. A direct transfer of the geometry from CAD to the bending machine reduces the risk of failures considerably. Each bus bar was mocked up with aluminum dummy first. 


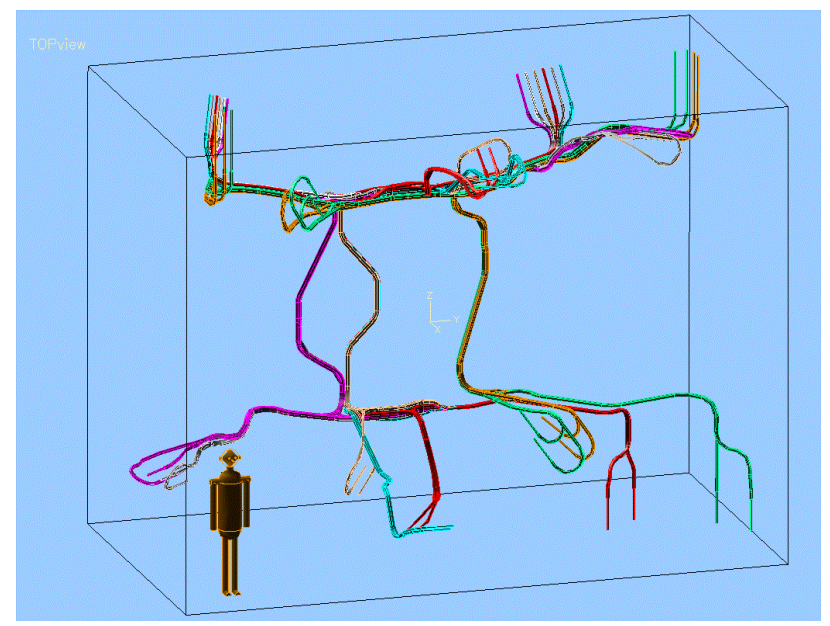

Figure 8. Schematic view on the bus system of one module.

The manufacturing and testing includes the straightening of the bus bars, the rounding of the square shaped bus bar, the three dimensional bending using a computer controlled bending machine, the insulation by two layers of Kapton and epoxy resin impregnated glass fibers, the application of conductive paint, and the Paschen, pressure, leak, and flow resistance test [7]-[9].

Special care was taken during bending of the bus bars. They are equipped with helium filled balloons compensating the dead weight during the bending process.

Numerous prototype tests have been performed at room temperature and at $77 \mathrm{~K}$ for qualification of the design and manufacturing process. Prior to the start of the series manufacturing the following qualification steps have been applied to test samples of bus bars: a $13 \mathrm{kV}$ high voltage test for one minute, an artificial aging by warming up to $50 \mathrm{C}$ for $168 \mathrm{~h}$, force displacement measurements up to $200 \mathrm{MPa}$ bending stress at $77 \mathrm{~K}, 5000$ mechanical cycles of displacements of $28 \mathrm{~mm}$ of a $0.5 \mathrm{~m}$ sample at $77 \mathrm{~K}, 20$ thermal cycles between room temperature and $77 \mathrm{~K}$, force displacement measurement up to $200 \mathrm{MPa}$ bending stress at $77 \mathrm{~K}$, Paschen test at $13 \mathrm{kV}$ at 15 different pressure levels.

The responsibility for the design and the fabrication of the bus system (bus bars, supports, joints) was taken over by the research centre Jülich (FZJ), Germany. The responsibility for the joint insulation and the assembly of all parts stayed at the IPP. The contract with the FZJ started in 2004, the first bus bar section was delivered in 2007. In 2010 the last bus bar was delivered and connected to the coils by IPP in spring 2011. The installation and insulation of the joints at the module separation area by IPP is running according to schedule.

\section{CURRENT LEADS}

The current leads provide the transfer of the electrical current from the room temperature bus bar system outside the cryostat to the superconducting parts inside the cryostat.

A special feature is the upside-down orientation of the current leads in W7-X. This orientation allows to save a lot of space in the vicinity of the machine, because no separate current lead cryostat is necessary and the ways to the power supplies, which are situated directly below the machine, are much shorter compared with an installation of the current leads in the "right" orientation directly on top of the machine. But the upside-down orientation could cause problems for optimal and stable operation due to the occurrence of free convection inside the heat exchanger [10].

The Karlsruhe Institute of Technology (KIT), Germany, has a lot of experience in the design and the fabrication of different types of current leads, e.g. for LHC and ITER. Therefore the KIT was chosen for the development, the production and the testing of the current leads for W7-X.

According to [11] the basic design developed for the ITER HTS current lead demonstrator is used as a common base for the current leads for W7-X. They consist of a copper heat exchanger at the warm end side, a high temperature superconductor part (Bi2223/AgAu tapes) and a copper bar with integrated Nb3Sn rods near the cold end side [11].

Fig. 9 shows a current lead where the outer stainless steel tube was already insulated and the two G10 flanges glued on it. At both ends the connections to the room temperature, power cables on the left and the superconducting bus bar on the right, are shown. At the cold end an extra contact cooling has been applied to absorb part of the heat load. It uses the helium from the return line of the coil casing cooling. The total weight of a current lead is about $260 \mathrm{~kg}$. 


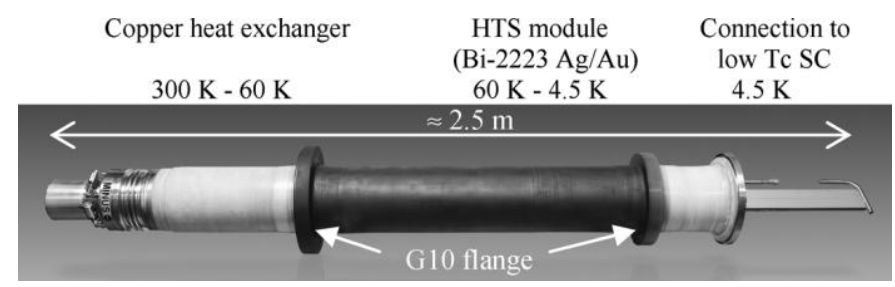

Figure 9. 18.2 kA HTS current lead for W7-X developed at the Karlsruhe Institute of Technology using Bi-2223/AgAu tapes [11]

After a qualification process two prototypes were built at first. Each of the prototype current leads has been instrumented with temperature sensors and voltage taps. Independently from the voltage taps quench detection wires are placed to observe the HTS part as well as the cold end region including the joint to the short circuit bus bar.

After completion of the prototype current lead manufacturing, two leads were installed in a test cryostat connected with a superconducting short circuit bus bar [12]. The connection is done by clamping using a $100 \mu \mathrm{m}$ thick Indium foil between the two Au-plated plane copper surfaces of the current lead cold end and the joint box of the short circuit bus bar. This joint box is equal to the joint box which will be used in W7-X. Also the superconductor, connecting the both current leads, is of the W7-X type. The connection at the warm end side was made with the original W7-X connection plug. All the measures secure the relevance of the test conditions for the operation in $\mathrm{W} 7-\mathrm{X}$ as much as possible.

The purpose of the prototype test was to confirm the design and to determine the operation parameters. The test comprises the following parts [13]: Measurement of heat load at $4.5 \mathrm{~K}$ with zero current, steady state operation at currents up to $20 \mathrm{kA}$ and long time test with $18.2 \mathrm{kA}$, ramp tests (simulating W7-X operation), Quench tests, Loss of mass flow (LOFA) tests.

The current leads prototypes were tested in two test campaigns. The whole test arrangement was cooled down to cryogenic temperature with a speed of about 10 Kelvin per hour. After the hydraulic and thermal stabilization the CLs were several times successfully loaded up to the maximum current of $18.2 \mathrm{kA}$. Also an overload test up to $20 \mathrm{kA}$ was performed to check the margin in terms of the current. A steady state test at $18.2 \mathrm{kA}$ over six hours did not show any problems. Also the test of a loss-of-Helium-flow accident showed sufficient time to de-energize the W7-X magnet system slowly, until a quench will occur. In the two test campaigns the safety margin of the superconducting parts was tested by induced quenches. The margin between the operating conditions and the achieved quench temperature meets the requirements. The necessary helium mass flow rates to operate the current leads fit to the expectations. [13].

In conclusion of the several tests one can state that the development of the current leads was successfully finished and that the worldwide unique upside down operation of current leads is manageable.

Meanwhile the series production has been started and per June 2011 four out of 14 current leads were produced, the test campaign of two of them was finished demonstrating a similar good performance with respect to the prototypes.

\section{CONCLUSIONS}

The superconducting magnet system of the experimental device Wendelstein 7-X consists of 50 non planar coils, 20 planar coils, 121 bus bar sections and 14 current leads. All types of coils and the bus system use the W7-X superconductor, a forced flow cable-in-conduit superconductor with 243 copper stabilized NbTi strands with an outer aluminum-alloy jacket. This allows the production of three dimensional coils. The achieved accuracy of the winding packs, for non planar as well as for planar coils, is nearly independent from its shape.

All coils were tested under cryogenic conditions up to the nominal current. The superconducting behavior was always as expected, but partly improper electrical insulation and several cold leaks in aluminum welds were found and had to be repaired.

The bus bar system, which interconnects the coils inside the cryostat, is very challenging due to the three dimensional routing and the space constraints. It requires a lot of manual work and tests directly at the W7-X machine.

The W7-X HTS current leads provide the transfer of the electrical current from the room temperature bus bar system outside the cryostat to the superconducting parts inside the cryostat. During the tests of the current leads it was confirmed that they can be operated successfully in upside down orientation.

The procurement and assembly of the superconducting magnet system has been running over nearly the whole construction period from 1998 until 2013. The first contracts with the industry about the delivery of components have been settled in 1998 and the last components will be delivered in 2012. The assembly started in 2005 with the installation of the first coil and will be finished with the last current lead installation in 2013. The first operation of the magnet system is planned in 2014 . 


\section{REFERENCES}

[1] R.K. Maix, V. Bagnato, M. Fricke, K. Heyn, T. Kluck, F. Lange, K. Riße, C. Sborchia, N. Valle, "Design, Production and QA Test Results of the NbTi CIC Conductors for the W7-X Magnet System," Journal of Physics: Conference Series 43 (2006), pp. 753-758

[2] Th. Rummel, K. Riße, H. Viebke, T. Bräuer and J. Kißlinger, “Accuracy of the construction of the superconducting coils for Wendelstein 7-X," IEEE Trans. Appl. Supercond. 14 (2004) (2 (June)), pp. 1394-1398.

[3] Th. Rummel, K. Riße, H. Ehmler, "Manufacture and test of the non-planar coils for WENDELSTEIN 7-X," Fusion Engineering and Design, Volumes 75-79, November 2005, Pages 117-121

[4] Riße, Th. Rummel, G. Ehrke and M. Köppen, "Design, Tests and Repair Procedures for the Electrical Insulation of the Superconducting W7-X Magnets," IEEE Transactions on Applied superconductivity, Vol. 20, No. 3, June 2010, pp. 447-450.

[5] H. Viebke, D. Gustke, T. Rummel, C. Sborchia, R. Schroeder, D. Williams, S. Bates, B. Leigh, R. Winter, "Lessons learned from the manufacture of the W7-X planar coils,", Journal of Physics: Conference Series 43 (2006), pp. 748-752

[6] H. Viebke, K. Hertel, J. Baldzuhn, G. Croari, L. Genini, B. Renard, L. Vieillard, “Acceptance tests of W7-X coils," Fusion Engineering and Design, Volume 84, Issues 7-11, pp. 1925-1927.

[7] O. Neubauer, A. Charl, G. Czymek, B. Giesen, M. Sauer, L. Scheibl, J. Schruff, R. Schick, A. Panin, A. John, S. Jung, K. Rummel, L. Wegener, "The busbar system for Wendelstein 7-X prepared for assembly and operational loads,", Fusion Engineering and Design, Volume 84, Issues 7-11, June 2009, pp. 14161419

[8] G. Czymek, B. Giesen, F. Harberts, A. Panin, M. Lennartz, U. Reisgen, W. Schuster, J. Wolters, K. Rummel, M. Czerwinski, H. Lentz and M. Ebner, "Design aspects of the joints for the busbar system of the Wendelstein 7-X stellarator," Fusion Engineering and Design 82, Issues 5-14, Pages 1467-1472.

[9] K. Rummel, M. Czerwinski, F. Hurd, A. John, H. Lentz, G. Czymek, B. Giesen, F. Harberts, S. A. Egorov, V. E. Korsunsky, I. Y. Rodin, P. Bruzzone, B. Stepanov, M. Vogel, "Test results from the full size prototype test of W7-X joint," Fusion Engineering and DesignVolume 82, Issues 5-14, , Pages 15261531.

[10] W.H. Fietz, R. Heller, A. Kienzler, and R. Lietzow, "Status of HTS current leads for WENDELSTEIN 7-X and JT-60SA", Fusion Engineering and Design 84 (2-6), (2009), pp. 776-77

[11] W.H. Fietz, R. Heller, A. Kienzler, and R. Lietzow, "High Temperature Superconductor Current Leads for WENDELSTEIN 7-X and JT-60SA", IEEE Trans. on Appl. Supercond. vol 19 no 3 (2009), pp. 2202-2205

[12] W. H. Fietz, S. Drotziger, S. Fink, M. Heiduk, R. Heller, A. Kopmann, C. Lange, R. Lietzow, T. Möhring, P. Rohr, T. Rummel, M. Süßer, "Test Arrangement for the W7-X HTS-Current Lead Prototype Testing,” IEEE Transactions on Applied Superconductivity, “ Vol. 21, No. 3, June 2011, pp. 10581061

[13] R. Heller, S. Drotziger, W.H. Fietz, S. Fink, M. Heiduk, A. Kienzler, C. Lange, R. Lietzow, T. Möhring, P. Rohr, T. Rummel, T. Mönnich, and K.-P. Buscher, "Test Results of the High Temperature Superconductor Prototype Current Leads for Wendelstein 7-X," IEEE Transactions on Applied Superconductivity,“ Vol. 21, No. 3, June 2011, pp. 1062-1065. 